\title{
Polycyclic Aromatic Hydrocarbons
}

National Cancer Institute

\section{Source}

National Cancer Institute. Polycyclic Aromatic Hydrocarbons. NCI Thesaurus. Code C761.

Polycyclic aromatic hydrocarbons (PAH) are a large class of organic compounds containing two or more fused aromatic rings made up of carbon and hydrogen atoms. They have high melting and boiling-points, low vapour pressure, water solubility, and are highly lipophilic. PAH are produced during incomplete combustion or pyrolysis of organic matter, are found in cigarette smoke, motor vehicle exhaust, used motor lubricating oil, broiled meat, coal tar, crude oil, creosote, roofing tar, dyes, plastics, and pesticides. Some members of PAH class were shown to have carcinogenic, genotoxic, and immunotoxic properties, developmental toxicity and affect reproductive health. $(\mathrm{NCl})$ 